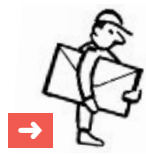

\section{Kritische Gedanken zur befremdlichen Einführung der Tarif-Position 00.0065}

Hier ist schon im Vorfeld von den verschiedenen Gremien leider schlecht informiert und zu wenig offen diskutiert worden, so dass sich nun viele potentielle Anwender dieser teils realitätsfremden, schlecht getarnt gewinnstreberischen Position geradezu schämen müssen (vgl. auch Leserbrief von Dr. A. Chavaz in der SÄZ 19/2009, S. 753): «Inkonvenienz-Entschädigung», «Taxe de dérangement», «Forfait per incomodo» als euphemistisch beschönigende sprachliche Monstrositäten! Als ob die Ausübung einer Berufstätigkeit etwas «Un-Genehmes» wäre, als ob Arbeit an sich eine «Störung», eine «Unbequemlichkeit» bedeutete - vielleicht für Faule und Müssiggänger ... Und wieder einmal mehr wird das Klischee von der habgierigen Krämerseele der Mediziner evoziert! Worin soll denn praktisch diese Inkonvenienz beim Hausbesuch bestehen? Dass man sich vom Sessel erheben, dem Verkehr aussetzen, eine Tasche schleppen und Treppen steigen muss? Doch umgekehrt werden ja inzwischen die Praxisräume weniger abgenutzt, verschmutzt und geheizt...

Die zuständige Stelle erklärt die Notwendigkeit der neuen Position «aufgrund der geringeren Produktivität bzw. der unterschiedlichen tarifarischen Ertragssituation, wenn der Arzt Besuche macht». Da müssen offenbar spezialärztliche Fachgesellschaften Pate gestanden haben, für die es ja wirklich bei Hausbesuchen nicht möglich ist, ihre ganze Praxiseinrichtung zu amortisieren. Jedoch dem gut ausgebildeten und gut ausgerüsteten Allgemeinarzt stehen bei Hausbesuch und Sprechstunden-Konsultation, wie ich mich aus meiner Landarzt-Zeit erinnere, tatsächlich ausgenommen Röntgen, Sonographie und Kolposkopie - genau dieselben Wertschöpfungsmöglichkeiten offen: So bewältigt er auch auswärts das ganze Spektrum: von Corneafremdkörper, Trommelfell-Parazentese, Tonsillarabszess, Zahnextraktion, über Magenspülung, EKG, Katheterismus und die gesamte Kleinchirurgie mit Wundbehandlung, Inzisionen und Exzisionen, Punktionen, Infiltrationen, Instillationen, inkl. Leitungs- und I.v.-Lokalanästhesie, evtl. Kurznarkose für Repositionen, auch Leuko/Thrombozytenzählung und Zytostatika-Infusion am Krankenbett, bis hin zu Hämorrhoiden- und Varizenbehandlung sowie gynäkologischen und geburtshilflichen
Eingriffen. Wozu da noch eine Extraprämie für Besuchstätigkeit? Für mich selber damals, im abgelegenen Gebiet mit rund 30 Besuchen pro Woche, hätten jährlich 1500 mal 40 Taxpunkte eine erkleckliche Mehreinnahme - und dies ohne jede Mehrleistung! sowie einen wahren Kostenschub für die lokale Krankenkasse bedeutet ... Und heute also beschert mir die neue Verrechnung ab März 2009 plötzlich eine Art von unverdientem Trinkgeld - beschämend! Wie viel aber dadurch landesweit ab Stichtag die Kostensteigerung auf der Patientenseite beträgt, mag die Statistik unschwer nachrechnen.

Ob vielleicht die Limitierung der Position nochmals überdacht werden müsste? Für Allgemeinmedizinische Praxen wie oben beschrieben, die freilich kaum mehr zeitgemäss sind, erscheint ihre Anwendung absolut nicht gerechtfertigt. Aber wie sich mit Zeit und Gesellschaft auch Arztbild und Erwartungen des Publikums wandeln, müssen die Strukturen im Gesundheitswesen eben nachziehen - nur womöglich nicht allzu brüsk!

\section{Dr. med. Hans R. Schwarz-Ammann,}

Porto Ronco

\section{Antwort auf den Leserbrief von Dr. med. Hans R. Schwarz-Ammann}

Sehr geehrter Herr Kollege

Ich kann Ihren Gedankengängen schlecht folgen und sehe in dieser Position überhaupt keine Habgierigkeiten und schlecht getarnte gewinnstrebende Position. Diese Position wurde in Zusammenarbeit mit den Grundversorger-Gesellschaften geschaffen, um die für die Patientinnen und Patienten wertvollen und kostengünstigen Hausbesuche zu unterstützen und zu fördern.

Die Besuchs-Inkonvenienz-Pauschale (BIP) deckt die Zeit ab, in welcher der Arzt nicht in der Praxis und unterwegs bei einem Hausbesuch ist. In dieser Zeit ist die Praxis nicht operativ, die ganzen Kosten (Miete, Löhne MPA usw.) stehen trotzdem an. Die Zeiten mit 30 Hausbesuchen pro Woche gehören der Vergangenheit an. Es ist heute wichtig, dass die Praxisärzte weiterhin Hausbesuche machen und diese auch sachgerecht entschädigt bekommen. Die Besuchs-Inkonvenienz-Pauschale hilft sicher mit, die Hausbesuche attraktiver zu machen. Sie dient auch zur Stärkung des Berufs des Grundversorgers.

Dr. med. Ernst Gähler Vizepräsident FMH, Verantwortlicher Ressort Tarife und Verträge 